\title{
The Comparison of In Vivo Properties of Water-Soluble HPMA-Based Polymer Conjugates with Doxorubicin Prepared by Controlled RAFT or Free Radical Polymerization
}

\author{
P. CHYTIL ${ }^{1}$, M. ŠÍROVÁ ${ }^{2}$, E. KOZIOLOVÁ ${ }^{1}$, K. ULBRICH ${ }^{1}$, B. ŘÍHOVÁ ${ }^{2}$, T. ETRYCH \\ ${ }^{1}$ Institute of Macromolecular Chemistry, Academy of Sciences of the Czech Republic, Prague, \\ Czech Republic, ${ }^{2}$ Institute of Microbiology, Academy of Sciences of the Czech Republic, Prague, \\ Czech Republic
}

Received June 12, 2015

Accepted June 16, 2015

\begin{abstract}
Summary
Two conjugates of anticancer drug doxorubicin (Dox) covalently bound by the hydrolytically degradable hydrazone bond to the polymer carrier based on water-soluble $\mathrm{N}$-(2-hydroxypropyl) methacrylamide (HPMA) copolymers were synthesized and their properties were compared, namely their behavior in vivo. The polymer carriers differed in dispersity due to different methods of synthesis; the carrier with relatively high dispersity (HD) was prepared by free radical polymerization $\left(M_{w}=29900 \mathrm{~g} / \mathrm{mol}\right.$, $\Theta=1.75)$ and the carrier with low dispersity (LD) by controlled radical polymerization $\left(M_{w}=30000 \mathrm{~g} / \mathrm{mol}, D=1.13\right)$. Both polymer-Dox conjugates showed prolonged blood circulation and tumor accumulation of the drug in comparison with the free drug; e.g. the tumor-to-blood ratio for the polymer-bound Dox was 35 times higher. The LD polymer-Dox conjugate exhibited moderately higher tumor accumulation than the HD one at a dose of $1 \times 15 \mathrm{mg}$ Dox (eq.)/kg. Also, their anti-tumor activity did not differ when injected at this dose. However, the increase of the dose to $1 \times 25 \mathrm{mg}$ Dox (eq.)/kg resulted in the enhanced therapeutic activity of the conjugates, especially of the LD one with $100 \%$ of long-term survivals. The dispersity of polymer drug carriers influenced the tumor accumulation rate, which affected the overall anti-cancer activity of polymer-drug conjugates.
\end{abstract}

\section{Key words}

HPMA copolymers • RAFT polymerization • Drug delivery system

- Controlled release $\bullet$ Doxorubicin

\section{Corresponding author}

P. Chytil, Institute of Macromolecular Chemistry, Academy of Sciences of the Czech Republic, Heyrovský Sq. 2, 16206
Prague 6, Czech Republic. Fax: +420-296 809 410. E-mail: chytil@imc.cas.cz

\section{Introduction}

Developing the highly efficient cancer therapy with reduced adverse side effects has become a desirable goal for numerous research teams over the last few decades. The majority of the cytostatic agents used in clinical practice are toxic for the tumor tissue and to a certain extent for the healthy tissues, too. Therefore, the administered dose limited by the toxicity towards the healthy tissues may be insufficient to kill the tumor cells. The drug delivery system, e.g. based on polymer drug carriers, transporting the cytostatic drug in an inactive form during blood circulation and delivering it to the tumor tissue is supposed to improve the cancer therapy outcome.

The higher anticancer activity of polymer-drug conjugates is induced by the polymer carrier accumulation in solid tumors due to the Enhanced Permeability and Retention (EPR) effect and by prolonged blood circulation guaranteeing sustained concentration in plasma (Maeda and Matsumura 1989). The accumulation rate of polymer carriers in solid tumors highly increases with the molecular weight $\left(M_{\mathrm{w}}\right)$ of polymer carriers (Seymour et al. 1995). However, the high molecular weight polymer carriers exceeding the renal excretion threshold should be biodegradable to prevent the polymer carrier retention in the body after the drug delivery.

$N$-(2-hydroxypropyl)methacrylamide (HPMA)based copolymers with the cytostatic agent, doxorubicin 
(Dox), bound by the biodegradable pH-sensitive hydrazone bond showed prolonged drug circulation and tumor accumulation, resulting in superior antitumor activity with reduced overall toxicity when compared to the free Dox (Mrkvan et al. 2005, Šírová et al. 2010). The same polymer carrier enabled the pH-sensitive attachment of various drugs; e.g. anticancer agents pirarubicin (Nakamura et al. 2014), paclitaxel or docetaxel (Etrych et al. 2010), mitomycin C (Kostkova et al. 2013), or anti-inflammatory drug dexamethasone (Krakovičová et al. 2009, Kostkova et al. 2011). Polymer conjugates containing the single drug alone or the combination of drugs showed also an excellent antitumor activity against various solid tumors in mice.

The most frequently used method for the synthesis of HPMA-based polymer carriers is classical free radical polymerization enabling the preparation of copolymers in the wide range of molecular weights and with dispersity close to 2 without polymer fractionation. However, the development of controlled radical polymerization, in particular Reversible additionfragmentation chain transfer (RAFT) polymerization, enabled the synthesis of precisely defined HPMA-based polymer carriers with low dispersity (about 1.1-1.2) (Moad et al. 2008). Moreover, the RAFT polymerization technique allows the preparation of (semi)telechelic polymer precursors employed, e.g. as building blocks in the synthesis of advanced polymer structures (Pan et al. 2011, Chytil et al. 2015).

In this study, we focused on the comparison of properties of the linear polymer-Dox conjugates of the same $M_{\mathrm{w}}$ but differing in dispersity, i.e. the conjugates prepared using free radical polymerization (Etrych et al. 2008) or controlled radical RAFT polymerization (Chytil et al. 2010). Since the physicochemical characteristics were studied in detail before, here, we describe the biological properties in vivo, i.e. body distribution and antitumor activity in mice. The main attention is paid to the influence of dispersity of the polymer carriers on antitumor therapy.

\section{Materials and Methods}

\section{Materials}

Methacryloyl chloride, 4,4'-azobis(4-cyanopentanoic acid), 2,2'-azobis(isobutyro-nitrile) (AIBN), $N$-ethylmaleimide trifluoroacetate, 6-aminohexanoic acid, methyl 6-aminohexanoate hydrochloride, $N, N^{\prime}$-dicyclohexylcarbodiimide, tert-butyl carbazate, trifluoroacetic acid (TFA), 2,4,6-trinitrobenzene-1-sulfonic acid (TNBSA) were purchased from Sigma-Aldrich Inc. Doxorubicin hydrochloride (Dox. $\mathrm{HCl}$ ) was purchased from Meiji Seika (Japan). All other chemicals and solvents were of analytical grade. Solvents were dried and purified by conventional procedures and distilled before use.

\section{Synthesis}

The synthesis and characterization of $N-(2-$ hydroxypropyl)methacrylamide (HPMA), (6-methacrylamido hexanoyl)hydrazine (MA-Ahex-NHNH${ }_{2}$ ) and $N$ (tert-butoxycarbonyl)-2-(6-methacrylamido hexanoyl) hydrazine (MA-Ahex-NHNH-Boc) monomers and of the chain transfer agent 4-cyano-4-thiobenzoylsulfanylpentanoic acid have already been published (Thang et al. 1999, Ulbrich et al. 2004, Chytil et al. 2010).

The polymer precursor with low dispersity (LD)-copolymer was synthesized by RAFT polymerization of HPMA with MA-Ahex-NHNH-Boc followed by terminal dithiobenzoate group removal and deprotection of hydrazide groups as described (Chytil et al. 2010). For polymerization AIBN was used as an initiator, 4-cyano-4-thiobenzoylsulfanyl-pentanoic acid as the RAFT chain transfer agent (CTA), and tertbutylalcohol as the solvent. The molar ratio of monomers: CTA:AIBN was 600:2:1. The molar ratio of HPMA and MA-Ahex-NHNH-Boc was 9:1. The total concentration of both monomers was $0.9 \mathrm{M}$.

The polymer precursor with high dispersity (HD)-copolymer was prepared by free radical polymerization of HPMA and MA-Ahex-NHNH $\mathrm{N}_{2}$ as described elsewhere (Etrych et al. 2008).

Both polymer-Dox conjugates were prepared by the reaction of the respective polymer precursors containing free hydrazide groups with Dox.HCl in methanol in the dark (Etrych et al. 2002). The polymerdrug conjugates were purified from the unbound drug by gel filtration, using a Sephadex LH-20 column and methanol as the eluent.

Physicochemical characterization of copolymers and their drug conjugates

The molecular weight and dispersity of copolymers and conjugates were determined by size exclusion chromatography (SEC): Shimadzu HPLC system equipped with Superose $6(300 \times 10 \mathrm{~mm} ; 13 \mu \mathrm{m})$, and UV-VIS (Shimadzu SPD-10AVvp), refractive index (RI) Optilab-rEX and multiangle light scattering (MALS) DAWN EOS detectors (Wyatt Technology Co.). The 
eluent was $0.3 \mathrm{M}$ sodium acetate buffer $\mathrm{pH}$ 6.5; flow-rate $0.5 \mathrm{ml} \cdot \mathrm{min}^{-1}$.

The content of hydrazide groups was determined by the modified TNBSA assay as described in the literature (Etrych et al. 2008). The total content of the polymer-bound Dox was measured by UV-VIS spectrophotometry in water (Etrych et al. 2008). The amount of the unbound Dox was determined by SEC from the relative area of the peak corresponding to the free drug and that corresponding to the sum of the free and polymer bound Dox using the HPLC system equipped with the TSKgel column G3000SWxl (300 x $7.8 \mathrm{~mm} ; 5 \mu \mathrm{m})$ and UV-VIS detection at $488 \mathrm{~nm}$.

Hydrodynamic radii $\left(R_{\mathrm{H}}\right)$ in a phosphate buffer (0.1 M, with $0.05 \mathrm{M} \mathrm{NaCl}$; polymer concentration: $0.01 \mathrm{~g} \cdot \mathrm{ml}^{-1}$ ) at $25^{\circ} \mathrm{C}$ were measured by dynamic light scattering (DLS) with the Nano-ZS instrument Zetasizer (ZEN3600, Malvern). The intensity of scattered light was detected at an angle $\theta=173^{\circ}$. The wavelength of laser was $632.8 \mathrm{~nm}$. For evaluation of DLS data, the DTS(Nano) program was used. The values were the mean of at least five independent measurements.

\section{In vitro release of Dox}

The rates of Dox release from the conjugates were investigated in phosphate buffers at $\mathrm{pH} 5.0$ or 7.4 $(0.1 \mathrm{M}$, with $0.05 \mathrm{M} \mathrm{NaCl})$ at $37{ }^{\circ} \mathrm{C}$, using the polymer concentration in the incubation buffer equivalent to $0.5 \mathrm{mM}$ Dox and using extraction of the released Dox into chloroform followed by HPLC analysis, as described previously (Etrych et al. 2002). The values are the mean of three independent experiments.

\section{Experimental animals and tumor model}

The inbred strain of mice C57BL/6 $(H-2 b$ haplotype), aged 8-12 weeks, was purchased from the Animal Centre of the Institute of Physiology, Academy of Sciences of the Czech Republic. All mice were housed in accordance with the approved guidelines and provided with food and water ad libitum. All studies were approved by the Institutional Laboratory Animal Care and Use Committee, and Department Committee of the Academy.

The murine EL4 T cell lymphoma cell line was purchased from ATCC (TIB-39) and maintained and cultivated as recommended by the provider.

\section{Blood clearance and Dox content in tumor tissue}

C57BL/6 male mice were subcutaneously inoculated with $1 \times 10^{5}$ EL4 lymphoma cells. When the tumor reached the volume of $100-200 \mathrm{~mm}^{3}$ (after 8 days), the mice were intravenously injected either with Dox.HCl $(5 \mathrm{mg} / \mathrm{kg}$ ) or polymer-Dox conjugates (15 mg Dox (eq.) $/ \mathrm{kg}$ ), two mice per group/interval. Then, blood, urine, and tumor tissue samples were taken at the predetermined intervals after the injection: $0.5,1,3,6,12,24,48$ and $72 \mathrm{~h}$ (blood and urine), and 12, 24, 48, and $72 \mathrm{~h}$ (tumors). To enable the urine collection, the mice were placed in metabolic cages, so that the urine was collected as the pooled sample from the two mice in each group. The blood samples $(100 \mu \mathrm{l})$ were collected into heparinized tubes, and tumors were excised, weighed, and mechanically homogenized. The samples were tested for the total contents of Dox, in the case of Dox-conjugates the sum of the released and polymer-bound Dox. Determination of the total Dox content was performed after quantitative acid hydrolysis to doxorubicinone in $1 \mathrm{M} \mathrm{HCl}$. After incubation for $1 \mathrm{~h}$ at $50^{\circ} \mathrm{C}$, doxorubicinone (formed aglycon of Dox) was extracted with chloroform, the organic phase was evaporated to dryness, the evaporation residue was completely dissolved in methanol and analyzed using the gradientbased HPLC Shimadzu system equipped with the reversed-phase column Chromolith Performance RP-18e $(4.6 \times 100 \mathrm{~mm})$ and the fluorescence detector (Shimadzu RF-10Axl) $\left(\lambda_{\text {exc }}=488 \mathrm{~nm}, \lambda_{\mathrm{em}}=560 \mathrm{~nm}\right)$ (Fraier et al. 1995). The calibration of the described method was conducted by injecting exact amounts of free Dox.HCl into blood, urine, and tumor samples obtained from untreated animals and then analyzed (homogenized, hydrolyzed, and extracted) as described above. The tumor-to-blood ratio was calculated as the ratio between Dox tumor content related to $1 \mathrm{~g}$ of the tissue and the Dox content in blood related to $1 \mathrm{ml}$ of blood. Statistical analysis was performed using the Student's t-test and MS Excell software. Levels of significance are stated in the text for each analysis.

\section{In vivo antitumor activity of the conjugates}

C57BL/6 females were subcutaneously transplanted with $1 \times 10^{5}$ EL4 T cell lymphoma cells on the right flank on day 0 . The mice in which palpable tumors reaching the volume of $100-200 \mathrm{~mm}^{3}$ developed within 8 days were intravenously treated with the conjugates diluted with PBS to $200 \mu$, as described in the Results. Controls were transplanted with the tumor cells and treated with PBS alone. The survival time, tumor size, and the number of long-term survivors were determined. Each experimental group consisted of eight animals. 
Table 1. The characteristics of copolymers and their drug conjugates.

\begin{tabular}{lcccccc}
\hline Sample & $\begin{array}{c}\boldsymbol{M}_{\mathbf{w}} \\
(\mathbf{g} / \mathbf{m o l})\end{array}$ & $\begin{array}{c}\boldsymbol{M}_{\mathbf{n}} \\
(\mathbf{g} / \mathbf{m o l})\end{array}$ & $\boldsymbol{D}$ & $\boldsymbol{R}_{\mathbf{H}}$ & $\begin{array}{c}\text { Hydrazide } \\
\text { content (mol\%) }\end{array}$ & $\begin{array}{c}\text { Dox } \\
\text { content (w\%) }\end{array}$ \\
\hline LD-copolymer & 30000 & 26800 & 1.13 & 4.1 & 7.2 & - \\
HD-copolymer & 29900 & 17000 & 1.75 & 3.9 & 5.6 & - \\
LD-conjugate & 38900 & 33000 & 1.18 & 4.8 & n.a. & n.a. \\
HD-conjugate & 37700 & 21800 & 1.73 & 4.5 & & 9.8 \\
\hline
\end{tabular}

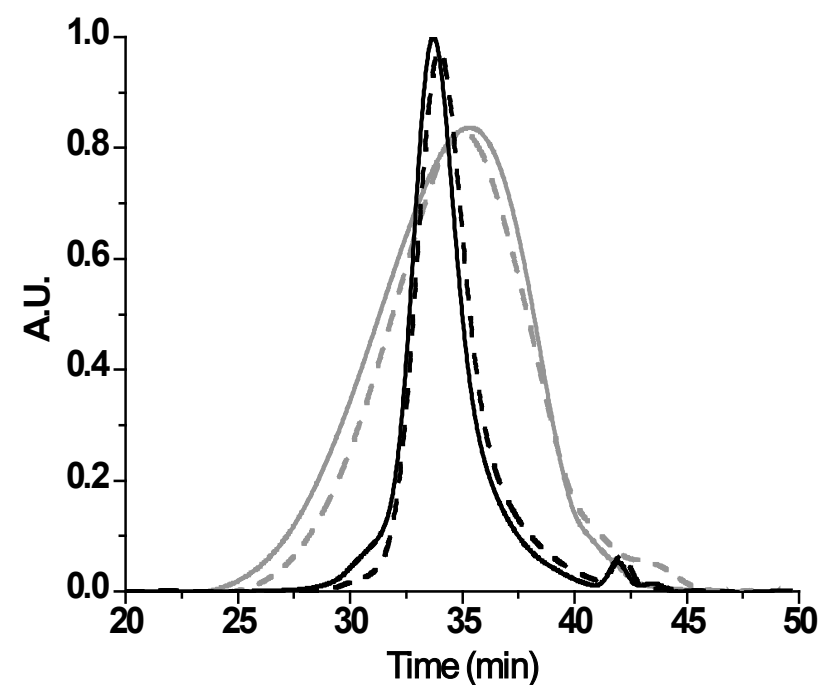

Fig. 1. SEC chromatograms of polymer carriers and their drug conjugates. (- LD-copolymer, - HD-copolymer, - - - HD-conjugate).

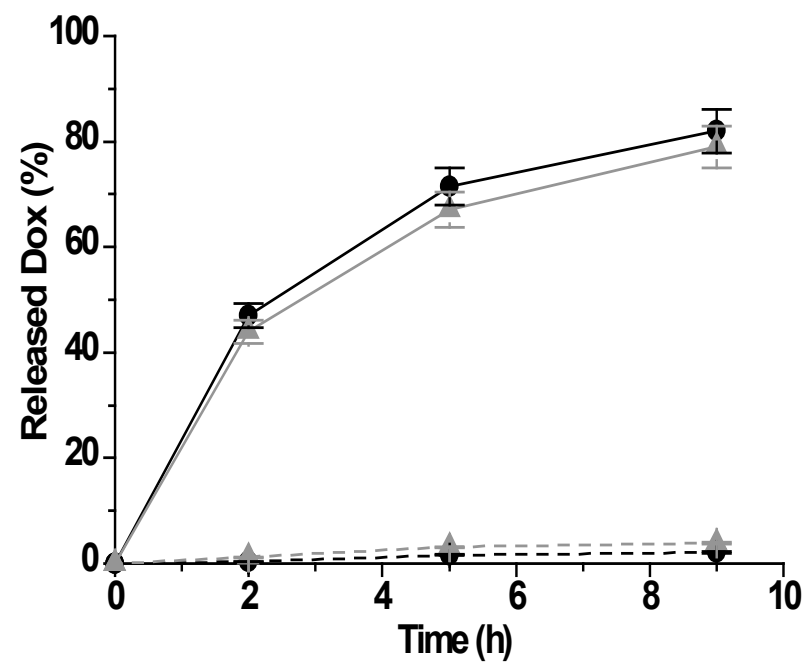

Fig. 2. Drug release from the polymer-Dox conjugates incubated in phosphate buffers at $37^{\circ} \mathrm{C}$. (LD-conjugate: - - $\mathrm{pH} \mathrm{5,}$ -- - - pH 7.4; HD-conjugate: $\triangle-\mathrm{pH} \mathrm{5,} \triangle$ - - pH 7.4).

\section{Results}

Synthesis of polymer precursors and their drug conjugates

Polymer precursors containing hydrazide groups were synthesized either by controlled radical polymerization (LD-copolymer) or by free radical polymerization (HD-copolymer) as described previously (Etrych et al. 2008, Chytil et al. 2010). Both copolymers had similar $M_{\mathrm{w}}$ of approximately $30000 \mathrm{~g} / \mathrm{mol}$ (see Table 1 for polymer characteristics). Nevertheless, the distribution of molecular weights differed, 1.13 and 1.75 for the LD- and HD-copolymer (Fig. 1). It means that while the LD-copolymer contained less than $10 \%$ of polymer chain fractions below $20000 \mathrm{~g} / \mathrm{mol}$, the HD-copolymer contained $50 \%$ of them. On the contrary, while molecular weight of almost all polymer chains of the LD-copolymer was lower than $40000 \mathrm{~g} / \mathrm{mol}$, there were $20 \%$ of such polymer chains in the HD-copolymer. The content of hydrazide groups for both copolymers did not differ much and it did not influence the hydrodynamic radii, which was approximately $4 \mathrm{~nm}$ for both copolymers.

Dox.HCl was bound to polymer precursors by the hydrazone bond in the high yield (approx. $95 \%$ ). The $M_{\mathrm{w}}$ and the size of the conjugates increased compared to the copolymers, however, their dispersity did not change significantly. No differences in reactivity during the conjugation reaction or physico-chemical properties of prepared polymer-Dox conjugates were observed.

\section{In vitro Dox release}

The Dox was released rapidly from both conjugates under mild acidic condition in the buffer of $\mathrm{pH} 5.0$ modeling the intracellular conditions of tumor cells. About $50 \%$ of Dox was released within $2 \mathrm{~h}$ and after $9 \mathrm{~h}$ the Dox release was almost complete (Fig. 2). On the contrary, at the $\mathrm{pH}$ corresponding to blood, only the negligible release of Dox from the carrier was observed. No significant differences in the release rates between the conjugates were observed. 

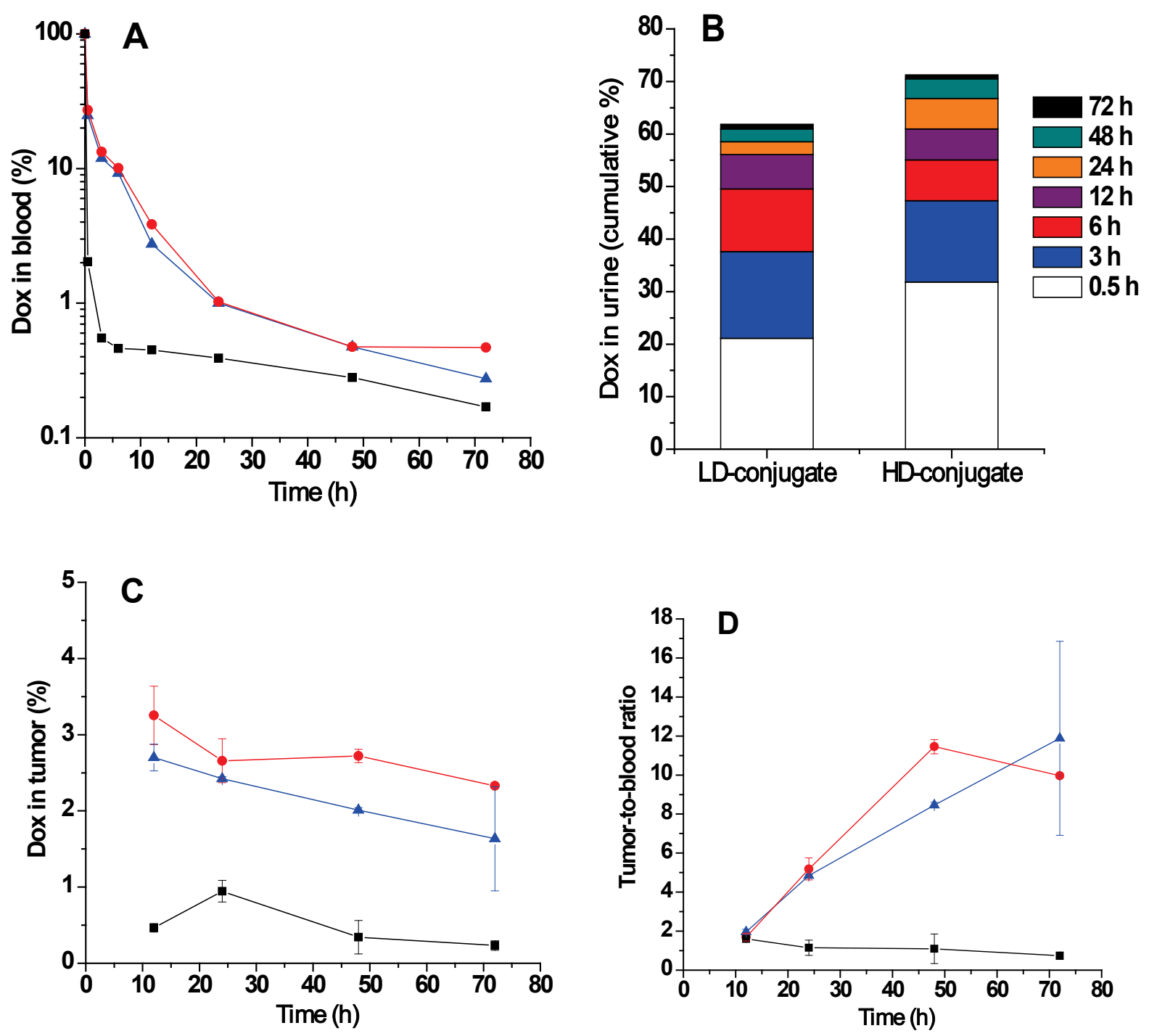

Fig. 3. Blood clearance (A), drug content in urine (B) and tumor (C) and tumor-to-blood ratio (D) in mouse bearing EL4 T-cell lymphoma; $1 \times 15 \mathrm{mg}$ Dox (eq.)/kg for conjugates, $1 \times 5 \mathrm{mg}$ Dox $/ \mathrm{kg}$ of free drug (•- LD-conjugate, $\Delta$ - HD-conjugate, - Dox. $\mathrm{HCl}$ ). In graph $\mathrm{A}$ and $\mathrm{B}$ the data shown are representative samples, in graph $\mathrm{C}$ and $\mathrm{D}$ the data shown are the mean of results from two animals.

Blood clearance and Dox content in urine and tumor tissue

The free Dox at a dose of 1 x $5 \mathrm{mg}$ Dox $/ \mathrm{kg}$ was eliminated from blood within minutes, only $2 \%$ of the total Dox dose was found in blood after $0.5 \mathrm{~h}$. However, blood clearance of the Dox-conjugates at a dose of $1 \mathrm{x}$ $15 \mathrm{mg}$ Dox (eq.) $/ \mathrm{kg}$ was much slower, $25 \%$ of the total Dox dose was remaining in blood after $0.5 \mathrm{~h}$ (Fig. 3A). The conjugates were cleared from blood within hours. Indeed, the Dox content in blood after $6 \mathrm{~h}$ was still $10 \%$ of total Dox dose; i.e. 20 times more than for free Dox. Blood clearance of the LD- and HD-conjugates was not significantly different $(p<0.05)$. The Dox content in urine in the first interval examined $(0.5 \mathrm{~h}$ after the injection) was higher for the HD-conjugate (32\%) than for the LD-conjugate (21\%). Nevertheless, the difference of the Dox content in urine for both conjugates at following intervals was not significant (Fig. 3B). In sum, there was found about $10 \%$ more of the eliminated dox in urine for the HD-conjugate within $72 \mathrm{~h}$, showing the impact of the low-molecular-weight polymer fraction on urine elimination.

The accumulation of the free Dox and conjugates in the EL4 lymphoma tumors was compared. The LD- and HD-conjugates efficiently accumulated in the tumor tissue. About $3 \%$ of the total Dox dose was found in tumor after $12 \mathrm{~h}$ for both conjugates, whereas the free Dox exhibited much lower tumor accumulation, 
$0.5 \%$ of the total Dox dose in tumor after $12 \mathrm{~h}$. The Dox accumulation rate for both conjugates was the highest after $12 \mathrm{~h}$ followed by the continuous slow decrease of the Dox content in the tumor. The Dox content of the LD-conjugate in tumor was slightly higher (about $20 \%$ ) than that of the HD-conjugate during the whole time period (Fig. 3C). While the tumor-to-blood ratio of the free Dox remained approx. 1, the tumor-to-blood ratio for both conjugates increased in the course of time (Fig. 3D) which corresponded with the decreasing blood concentration of polymer conjugates. The difference between tumor-to-blood ratios for both polymer conjugates was not significant.

\section{In vivo antitumor activity}

The in vivo therapeutic effect of the conjugates was evaluated in the EL4 $\mathrm{T}$ cell lymphoma-bearing C57BL $/ 6$ mice. At the dose of $1 \times 15 \mathrm{mg}$ Dox (eq.) $/ \mathrm{kg}$, both conjugates inhibited the tumor growth to the similar extent and cured the equal proportion of the animals (5 from 8 mice) (Fig. 4). However, at a dose of $1 \times 25 \mathrm{mg}$ Dox (eq.) $/ \mathrm{kg}$ the LD-conjugate cured all mice, whereas the HD-conjugate cured only 6 of 8 treated animals. The overall survival of the treated mice for the LD- and HD-conjugates at a dose of $1 \times 25 \mathrm{mg}$ Dox (eq.)/kg was significantly different $(p<0.01)$.

The overall survival correlated with the tumor size after the treatment with polymer conjugates. At a dose of $1 \times 15 \mathrm{mg}$ Dox (eq.) $/ \mathrm{kg}$ the tumor size decreased significantly; some tumors regressed completely after the treatment with both conjugates. The differences in the tumor size after the treatment with the LD- and HD-conjugates at a dose of $1 \times 15 \mathrm{mg}$ Dox (eq.) $/ \mathrm{kg}$ were not statistically different $(p<0.05)$, and the rate of tumor growth was moderately faster in the group treated with the HD-conjugate. After the treatment with LD-conjugate at a dose of $1 \times 25 \mathrm{mg}$ Dox (eq.) $/ \mathrm{kg}$ the tumors of all treated mice disappeared by day 24 , and all the mice remained tumor-free whereas the treatment with the HD-conjugate at the same dose first led to the tumor disappearance, but by day 28 and 48, the tumors reappeared in two animals from this group (Fig. 4A).

\section{Discussion}

Synthesis of polymer precursors and their drug conjugates

The polymer backbone of HPMA-based copolymers is not biodegradable. Therefore, only
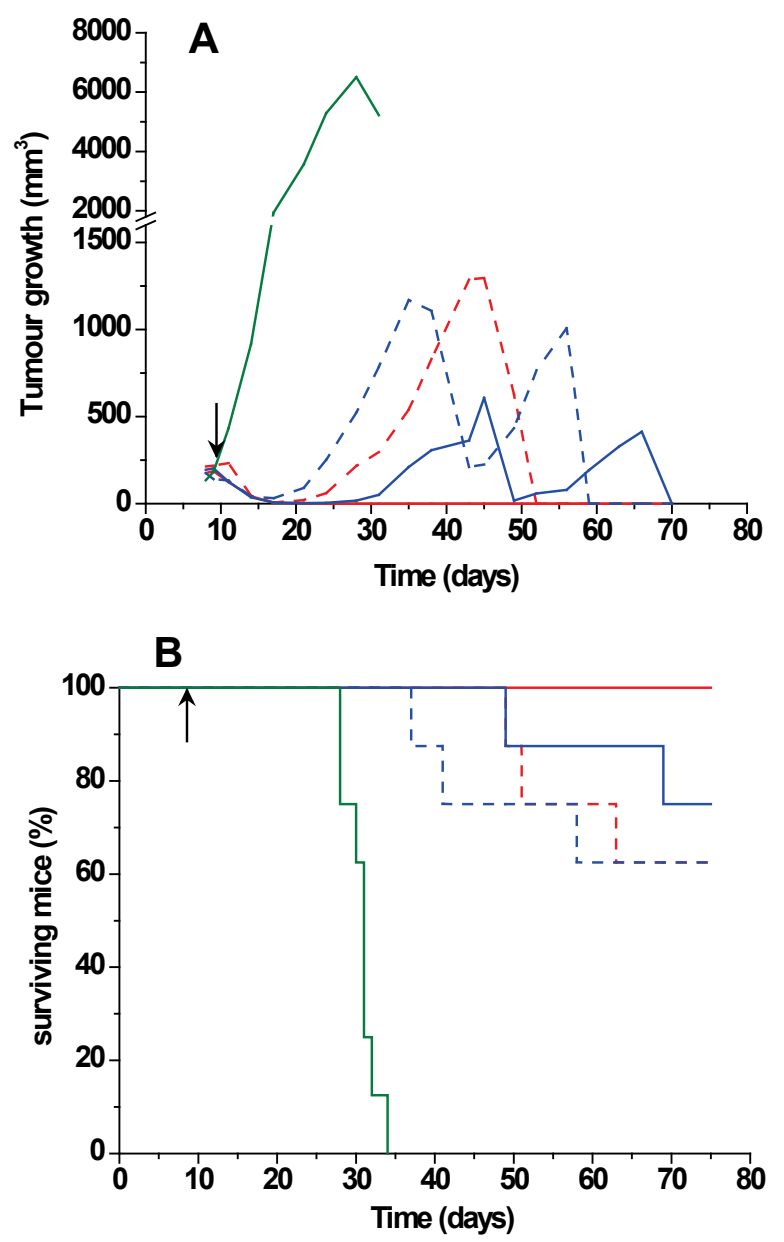

Fig. 4. In vivo effect of polymer-Dox conjugates on the growth of $T$ cell lymphoma EL-4 (A), survival of mice (B) (LD-conjugate: - $1 \times 25 \mathrm{mg}$ Dox (eq.)/kg, - - - $1 \times 15 \mathrm{mg}$ Dox (eq.)/kg; HD-conjugate: - 1 x $25 \mathrm{mg}$ Dox (eq.)/kg, - - - 1 x $15 \mathrm{mg}$ Dox (eq.)/kg; — controls). Arrow, administration of the treatment.

polymers with molecular weights under the limit of renal filtration $\left(M_{\mathrm{w}}\right.$ below $\left.50000 \mathrm{~g} / \mathrm{mol}\right)$ can be used as carriers in drug delivery systems. Polymers with higher molecular weights could potentially accumulate in the body, possibly leading to side effects. $M_{\mathrm{w}}$ of the HPMA copolymer hydrazone conjugate, prepared by uncontrolled free radical polymerization and evaluated for its in vivo anti-cancer activity, was about 25000 $30000 \mathrm{~g} / \mathrm{mol}$ (Etrych et al. 2008, Šírová et al. 2010). Thus, the controlled RAFT polymerization conditions were optimized with the intention of obtaining copolymers with the comparable $M_{\mathrm{w}}$ (Chytil et al. 2010). Although the synthetic procedure consisted in polymerization, the removal of terminal dithiobenzoate group and deprotection of hydrazide groups, the almost monodispersed LD-copolymer was prepared. It means 
that the majority of its polymer chains had the molecular weight about $30000 \mathrm{~g} / \mathrm{mol}$. On the contrary, the content of the lower-molecular-weight fraction was quite high in the case of the HD-copolymer prepared by free radical polymerization. Vice versa, a significant amount of polymer chains with higher molecular weights was detected in the HD-copolymer sample.

\section{In vitro Dox release}

The results of the in vitro drug release experiments in mild acidic and neutral buffers showed that the hydrazone bond was hydrolyzed quite fast at $\mathrm{pH}$ below 7 during incubation of both polymer-Dox conjugates. As expected, the dispersity did not influence the hydrolysis rate. Thus, the cytostatic agent Dox can be released from both conjugates in the slightly acidic environment of the target tumor tissue or the endosomes/lysosomes of tumor cells irrespective of the conjugate dispersity.

Blood clearance and Dox content in urine and tumor tissue

The advantage of the polymer-bound Dox against the free Dox was demonstrated many times before. Also here, prolonged circulation in blood and enhanced solid tumor accumulation was showed. More importantly, the comparison of the accumulation rate for the two polymer conjugates with different dispersity was performed. We expected the HD-conjugate to be eliminated faster by renal filtration than the LDconjugate due to its higher amount of lower-molecularweight polymer chains. This hypothesis was supported by the relatively high Dox content from the HD-conjugate determined in urine in the first $30 \mathrm{~min}$ interval. On the contrary, the HD-conjugate contained also a certain amount of polymer chains of much higher molecular weight than is the renal threshold ( $M_{\mathrm{w}}$ approx. 45000 $\mathrm{g} / \mathrm{mol}$ ) and which could circulate much longer in the body. Overall, the slightly higher amount of the HDconjugate was found in urine within $72 \mathrm{~h}$ showing the influence of higher dispersity of the polymer carrier on the rate of urine elimination.

However, the Dox content in blood was comparable for both conjugates and the Dox content in tumor was slightly higher, about $20 \%$, for the LD-conjugate showing moderately higher tumor accumulation. Nevertheless, the difference in the drug content either in blood or tumor was not statistically significant. Also tumor-to-blood ratio values, indicating enhanced accumulation in solid tumor, did not significantly differ. Both parameters correspond to the applied dose of 1 x $15 \mathrm{mg}$ Dox (eq.) $/ \mathrm{kg}$. Thus, any differences in antitumor activity probably could not be expected at this dose. However, in the case of administration of the higher dose than 1 x $15 \mathrm{mg}$ Dox (eq.) $/ \mathrm{kg}$, which is suboptimal for the therapeutic outcome, the potential difference between the conjugates may become apparent and even statistically relevant.

\section{In vivo antitumor activity}

Based on previous experiments, the LD and HD-conjugates were administered at a dose of 1 x $15 \mathrm{mg}$ Dox (eq.) $/ \mathrm{kg}$ which is suboptimal in respect of the treatment of established EL4 lymphoma; and at a dose of $1 \times 25 \mathrm{mg}$ Dox (eq.)/kg of the conjugated Dox which is the optimal dose and is still far from the maximal tolerated dose (MTD) of the HD-conjugate, expected to be about $85 \mathrm{mg}$ Dox (eq.) $/ \mathrm{kg}$. The treatment by the free Dox is unsatisfactory as some proportion of animals could be cured only at doses close to MTD, thus they are harmed by late toxicity of the drug. At lower Dox doses, the treated animals survived usually not longer than controls (Mrkvan et al. 2005, Etrych et al. 2008).

The similar antitumor activity of conjugates at the dose of 1 x $15 \mathrm{mg}$ Dox (eq.)/kg was in accordance with the results obtained in the biodistribution experiment at the same dose. Most probably, the higher antitumor activity of the LD-conjugate at the dose of 1 x $25 \mathrm{mg}$ Dox (eq.) $/ \mathrm{kg}$ can be ascribed to the enhanced tumor accumulation due to the retention of polymer chains with sufficient molecular weights. Moreover, the molecular weight of the HPMA-based polymer conjugates with low dispersity prepared by RAFT polymerization can be significantly increased without exceeding the limit of renal filtration; i.e. the molecular weight of the longest polymer chains should be underneath the limit. It can be expected that such polymer-drug conjugates will be more efficient in the treatment of solid tumors and still capable of the carrier removal from the organism.

\section{Conclusions}

The linear water-soluble HPMA-based polymerdrug conjugates bearing the anticancer drug Dox bound by the $\mathrm{pH}$-sensitive hydrazone bond were synthesized and characterized. Their polymer precursors had the same $M_{\mathrm{w}}$ of about $30000 \mathrm{~g} / \mathrm{mol}$, but they differed in dispersity $(\nexists$ $=1.13$ or 1.75 ) due to the utilization of controlled RAFT 
or free radical polymerization. Considering the same drug release rate determined in vitro, the potential influence on biodistribution or antitumor activity in vivo can be attributed to the different dispersity of the carriers. Although moderately enhanced drug accumulation in EL4 T-cell lymphoma tumors was determined for the monodispersed LD-conjugate, the differences were not statistically significant. Thus, the therapeutic activity of both conjugates at the same suboptimal dose of $1 \times 15 \mathrm{mg}$ Dox (eq.) $/ \mathrm{kg}$ did not differ (63\% of long-termed survivals). As expected, the increase of the dose to $1 \times 25$ $\mathrm{mg}$ Dox (eq.) $/ \mathrm{kg}$ resulted in the significantly increased antitumor activity of polymer-Dox conjugates. The application of the LD-conjugate at the higher dose was more efficient (100\% of long-termed survivals) than that of the HD-conjugate ( $75 \%$ of long-termed survivals). We suppose that the absence of lower-molecular-weight polymer chains in the LD-conjugate facilitated the prolonged blood circulation and enhanced tumor accumulation of the LD-conjugate, which could result in better therapeutic activity at the higher dose. Further experiments proving such a hypothesis are under way.

\section{Conflict of Interest}

There is no conflict of interest.

\section{Acknowledgements}

This work was supported by the Ministry of Education, Youth and Sports of the Czech Republic (Grant No.EE2.3.30.0029) and by the project "BIOCEV Biotechnology and Biomedicine Centre of the Academy of Sciences and Charles University" (CZ.1.05/1.1.00/ 02.0109), from the European Regional Development Fund.

\section{References}

CHYTIL P, ETRYCH T, KŘÍŽ J, ŠUBR V, ULBRICH K: N-(2-Hydroxypropyl)methacrylamide-based polymer conjugates with $\mathrm{pH}$-controlled activation of doxorubicin for cell-specific or passive tumour targeting. Synthesis by RAFT polymerisation and physicochemical characterisation. Eur J Pharm Sci 41: 473-482, 2010.

CHYTIL P, KOZIOLOVÁ E, JANOUŠKOVÁ O, KOSTKA L, ULBRICH K, ETRYCH T: Synthesis and properties of star HPMA copolymer nanocarriers synthesised by RAFT polymerisation designed for selective anticancer drug delivery and imaging. Macromol Biosci 15: 839-859, 2015.

ETRYCH T, CHYTIL P, JELÍNKOVÁ M, ŘÍHOVÁ B, ULBRICH K: Synthesis of HPMA copolymers containing doxorubicin bound via a hydrazone linkage. Effect of spacer on drug release and in vitro cytotoxicity. Macromol Biosci 2: 43-52, 2002.

ETRYCH T, MRKVAN T, CHYTIL P, KOŇÁK Č, ŘÍHOVÁ B, ULBRICH K: N-(2-hydroxypropyl)methacrylamidebased polymer conjugates with $\mathrm{pH}$-controlled activation of doxorubicin. I. New synthesis, physicochemical characterization and preliminary biological evaluation. J Appl Polym Sci 109: 3050-3061, 2008.

ETRYCH T, ŠÍROVÁ M, STAROVOYTOVA L, ŘíHOVÁ B, ULBRICH K: HPMA Copolymer conjugates of paclitaxel and docetaxel with pH-controlled drug release. Mol Pharm 7: 1015-1026, 2010.

FRAIER D, FRIGERIO E, PIANEZZOLA E, STROLIN BENEDETTI M, CASSIDY J, VASEY P: A sensitive procedure for the quantitation of free and $N$-(2-hydroxypropyl)methacrylamide polymer-bound doxorubicin (PK1) and some of its metabolites, 13-dihydrodoxorubicin, 13-dihydrodoxorubicinone and doxorubicinone, in human plasma and urine by reversed-phase HPLC with fluorimetric detection. $J$ Pharm Biomed Anal 13: 625-633, 1995.

KOSTKOVÁ H, ETRYCH T, ŘÍHOVÁ B, ULBRICH K: Synergistic effect of HPMA copolymer-bound doxorubicin and dexamethasone in vivo on mouse lymphomas. J Bioact Compat Polym 26: 270-286, 2011.

KOSTKOVÁ H, ETRYCH T, ŘÍHOVÁ B, KOSTKA L, STAROVOYTOVA L, KOVÁŘ M, ULBRICH K: HPMA Copolymer conjugates of DOX and mitomycin $\mathrm{C}$ for combination therapy: physicochemical characterization, cytotoxic effects, combination index analysis, and anti-tumor efficacy. Macromol Biosci 13: 1648-1660, 2013.

KRAKOVIČOVÁ H, ETRYCH T, ULBRICH K: HPMA-based polymer conjugates with drug combination. Eur $J$ Pharm Sci 37: 405-412, 2009.

MAEDA H, MATSUMURA Y: Tumoritropic and lymphotropic principles of macromolecular drugs. Crit Rev Ther Drug Carrier Syst 6: 193-210, 1989. 
MOAD G, RIZZARDO E, THANG SH: Radical addition-fragmentation chemistry in polymer synthesis. Polymer 49: 1079-1131, 2008.

MRKVAN T, ŠÍROVÁ M, ETRYCH T, CHYTIL P, STROHALM J, PLOCOVÁ D, ULBRICH K, ŘíHOVÁ B: Chemotherapy based on HPMA copolymer conjugates with $\mathrm{pH}$-controlled release of doxorubicin triggers antitumor immunity. J Control Release 110: 119-129, 2005.

NAKAMURA H, ETRYCH T, CHYTIL P, OHKUB, M, FANG J, ULBRICH K, MAEDA H: Two step mechanisms of tumor selective delivery of $\mathrm{N}$-(2-hydroxypropyl)methacrylamide copolymer conjugated with pirarubicin via an acid-cleavable linkage. $J$ Control Release 174: 81-87, 2014.

PAN HZ, YANG JY, KOPEČKOVÁ P, KOPEČEK J: Backbone degradable multiblock $N$-(2-hydroxypropyl) methacrylamide copolymer conjugates via reversible addition-fragmentation chain transfer polymerization and thiol-ene coupling reaction. Biomacromolecules 12: 247-252, 2011.

SEYMOUR LW, MIYAMOTO Y, MAEDA H, BRERETON M, STROHALM J, ULBRICH K, DUNCAN R: Influence of molecular-weight on passive tumor accumulation of a soluble macromolecular drug carrier. Eur $J$ Cancer 31A: 766-770, 1995.

ŠÍROVÁ M, MRKVAN T, ETRYCH T, CHYTIL P, ROSSMANN P, IBRAHIMOVÁ M, KOVÁŘ L, ULBRICH K, ŘÍHOVÁ B: Preclinical evaluation of linear HPMA-doxorubicin conjugates with pH-Sensitive drug release: efficacy, safety, and immunomodulating activity in murine model. Pharm Res 27: 200-208, 2010.

THANG SH, CHONG YK, MAYADUNNE RTA, MOAD G, RIZZARDO E: A novel synthesis of functional dithioesters, dithiocarbamates, xanthates and trithiocarbonates. Tetrahedron Lett 40: 2435-2438, 1999.

ULBRICH K, ETRYCH T, CHYTIL P, JELÍNKOVÁ M, ŘÍHOVÁ B: Antibody-targeted polymer-doxorubicin conjugates with pH-controlled activation. J Drug Target 12: 477-489, 2004. 